\title{
Measurement and simulation of the suspension velocity of flax threshing material using CFD-DEM
}

\author{
Fei Dai ${ }^{1}$, Wenjuan Guo ${ }^{1,2}$, Xuefeng Song ${ }^{1}$, Ruijie Shi ${ }^{1}$, Jiangfei $\mathrm{Qu}^{1}$, Wuyun Zhao ${ }^{1 *}$ \\ (1. College of Mechanical and Electrical Engineering, Gansu Agricultural University, Lanzhou 730070, China; \\ 2. School of Cyber Security, Gansu University of Political Science and Law, Lanzhou 730070, China)
}

\begin{abstract}
In order to explore the aerodynamics characteristics of flax threshing material, and accurately obtain the movement trajectory of the material of each component in air-screen cleaning, the suspension velocities of flax grains, capsules, short stalks and capsule husks at different stages were measured by means of the suspension velocity device. The experimental results showed that the suspension velocity range was 4.55-8.64 m/s for flax grains, $6.46-10.90 \mathrm{~m} / \mathrm{s}$ for flax capsules, 3.23-7.75 m/s for flax short stalks, and 1.06-4.21 m/s for flax capsule shells. Based on the experimental results, the overall interval distribution of each component of flax threshing material and the separation characteristics were discussed and the discrete element model of each component of the flax threshing material was established. Through simulation measurement of angle of repose of the material and the sliding friction angle with steel, the reliability of the established model was verified. The gas-solid coupling method was used to simulate the suspension velocity of each component of the flax threshing material, and the suspension velocity of the four components of flax threshing material was obtained. The simulation measurement results were within the actual measurement range, showing that the test results were basically in line with the simulation results. The simulation on the suspension velocity of different components of flax threshing material based on gas-solid coupling had high precision degree. Therefore, the feasibility of the suspension velocity of the flax threshing material measured in the simulation test based on CFD-DEM coupling was verified.
\end{abstract}

Keywords: flax, threshing material, suspension velocity, CFD-DEM, numerical simulation

DOI: $10.25165 /$ j.ijabe.20211405.6651

Citation: Dai F, Guo W J, Song X F, Shi R J, Qu J F, Zhao W Y. Measurement and simulation of the suspension velocity of flax threshing material using CFD-DEM. Int J Agric \& Biol Eng, 2021; 14(5): 230-237.

\section{Introduction}

The suspension velocity of agricultural materials refers to the velocity of the agricultural materials relative to the airflow when they are suspended at a certain height under the action of a vertical upward airflow. Its value is equal to the absolute velocity of the airflow. The study on suspension velocity of agricultural materials can provide important basic data of cleaning equipment and technology and offer reference in the design of the key mechanisms and selecting working parameters ${ }^{[1]}$.

In recent years, the research on the movement law of agricultural material flow in agricultural machinery equipment and its separation and cleaning characteristics has become one of the research hotspots in the field of mechanized crop harvesting ${ }^{[2]}$. Gorial $^{[3]}$ studied the suspension speed and suspension coefficient of grains and straws through experiments; Ragab et al. ${ }^{[4]}$ studied the physical characteristics and aerodynamic characteristics of walnuts

\section{Received date: 2021-04-03 Accepted date: 2021-08-15}

Biographies: Fei Dai, PhD, Associate Professor, research interests: design of agricultural mechanization equipment, Email: daifei@gsau.edu.cn; Wenjuan Guo, $\mathrm{PhD}$ candidate, research interests: computer simulation, Email: 565105996@qq.com; Xuefeng Song, Lecturer, research interests: agricultural mechanization engineering, Email: 549349477@qq.com; Ruijie Shi, PhD candidate, research interests: agricultural mechanization engineering, Email: 1139230110@qq.com; Jiangfei Qu, MS candidate, research interests: agricultural mechanization engineering, Email: 1769817736@qq.com.

*Corresponding author: Wuyun Zhao, PhD, Professor, research interests: farm machine and mechanical reliability. College of Mechanical and Electrical Engineering, Gansu Agricultural University, Lanzhou 730070, China. Tel: +86-451-7632472, Email: zhaowy@gsau.edu.cn. to reveal the influence of walnut moisture content on their suspension velocity. In China, researchers carried out simulation studies and analyses on the suspension characteristics and suspension velocity of peanuts ${ }^{[5]}$, walnuts ${ }^{[6]}$, and rape $^{[7]}$, pseudo-ginseng ${ }^{[8]}$, red dates ${ }^{[9]}$ and millet $^{[1]}$ by the suspension velocity measurement devices by adjusting airflow speed. In addition to the air velocity of the test device, the suspension velocity of agricultural material is mainly related to the shape, windward area and surface characteristics of the material ${ }^{[10]}$. The components of flax threshing material are relatively complex. Flax grains, capsule husks, short stalks and unthreshed capsules are the main components of the threshing material, whose shape and weight of are different. Therefore, to further study on the separation and cleaning mechanism of flax threshing material requires, it is necessary to measure the suspension velocity of each component material to obtain the aerodynamic characteristic parameters of them, and to find out the overlapping range of the winnowing speed of each component material, to offer reference to the design of the separation and cleaning device for flax threshing material.

At the same time, based on the CFD-DEM gas-solid flow coupling simulation, it can be predicted that the suspension velocity of agricultural materials has relatively high precision. Among them, Mekonnen et al. ${ }^{[11]}$ used CFD to study the effects of different vortex wall positions on the flow field of the combine harvester's cross-flow fan; Yuan et al. ${ }^{[12]}$ used the DEM-CFD gas-solid coupling method to simulate and analyze the movement and the screening characteristics of paddy threshing mixture in a cylinder sieve. Jiang et al. ${ }^{[13]}$ simulated and tested the grain movement in the separation chamber of the combine harvester based on the 
CFD-DEM gas-solid coupling theory; Dai et al. ${ }^{[14]}$ simulated and tested the separation and cleaning process of flax threshing material based on CFD-DEM gas-solid coupling theory. Therefore, existing studies have shown that the application of gas-solid coupling theory has theoretical value and practical application significance for the analysis of the aerodynamic characteristics of each component of flax threshing material and the research of separation and cleaning devices, which can improve R\&D efficiency and save costs.

\section{Structure of the device and working principles}

\subsection{Structure}

The structure of the device for measuring the suspension velocity of flax threshing material is shown in Figure $1^{[1,15]}$. It is mainly composed of the material holding net, the feed inlet, the anemometer, the lower VR-tube, the tapered observation tube, the upper VR-tube, the suspension ruler, the grid tube, the centrifugal fan, the rack, the material resistance net, the connection device, and the frequency converter and the electric motor.

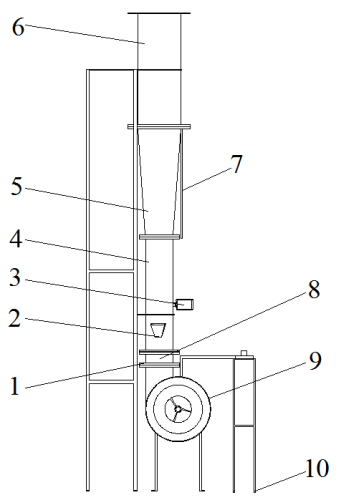

a. Structure of the device

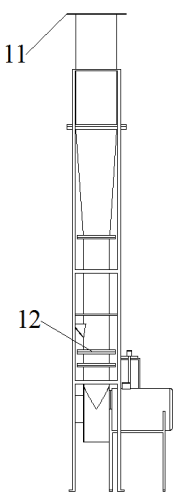
1. Material holding net 2. Feed inlet 3. Anemometer 4. Lower VR-tube 5. Tapered observation tube 6. Upper VR-tube 7. Suspension ruler 8. Grid tube 9. Centrifugal fan 10. Rack 11. Material resistance net 12. Connection device

Figure 1 Flax threshing material suspension velocity measuring device

Main technical parameters of the device for measuring the suspension velocity of flax threshing material are shown in Table 1.

Table.1 Technical parameters of flax threshing material suspension velocity measuring device

\begin{tabular}{lc}
\hline \multicolumn{1}{c}{ Parameters } & Values \\
\hline Size $($ Length $\times$ width $\times$ height $) /(\mathrm{mm} \times \mathrm{mm} \times \mathrm{mm})$ & $1800 \times 1100 \times 4200$ \\
Power/kW & 7.5 \\
Range of flow velocity $/\left(\mathrm{m} \cdot \mathrm{s}^{-1}\right)$ & $\leq 40$ \\
Inside diameter of lower VR-tube $/ \mathrm{mm}$ & 240 \\
Inside diameter of above VR-tube $/ \mathrm{mm}$ & 380 \\
Inclination angle of the tapered observation tube $/\left(^{\circ}\right)$ & 4 \\
Effective observation height $/ \mathrm{mm}$ & $0-1000$
\end{tabular}

Specification of the material holding net and material resistance net

20-mesh nylon net

\subsection{Measuring method for testing the suspension velocity}

When using the device for measuring the suspension velocity of the flax threshing material, the different components of the threshing material to be tested are classified and weighed, and the material is placed on the holding net in the lower VR-tube under the measuring device. Then, the fan speed is changed by adjusting the frequency converter, so that the material is stably suspended at about one-third of the overall height of the tapered observation tube of the device (the first stage of suspension), two-thirds (the second stage of suspension) and the top (the third stage of suspension). At this time, the anemometer obtains the flow velocity value at the lower end of the tapered observation tube, then the suspension height was measured by the suspension height scale of the device, and finally the suspension velocity of each component of the flax threshing material was calculated by Equation (1) ${ }^{[1]}$.

$$
v_{p}=\bar{v}\left(\frac{R}{R+H \tan \theta}\right)^{2}
$$

where, $\bar{v}$ is the mean value of measured flow velocity, $\mathrm{m} / \mathrm{s} ; R$ is the small end radius of the tapered observation tube, $240 \mathrm{~mm} ; H$ is the suspension height of the material in the tapered observation tube, $\mathrm{mm}$; the effective height for the tapered observation tube is among 0-1000 $\mathrm{mm}$, and can be calculated based on specific suspension height; $\theta$ is the inclination angle of the tapered observation tube, which was determined as $4^{\circ}$.

Figure 2 shows the three-stage height range of each component of the flax threshing material at the suspension velocity in the tapered observation tube. With the help of the intake end of the Pitot tube in the lower VR-tube, the intelligent anemometer can display the pressure, flow velocity and flow rate of different materials at different suspension stages.

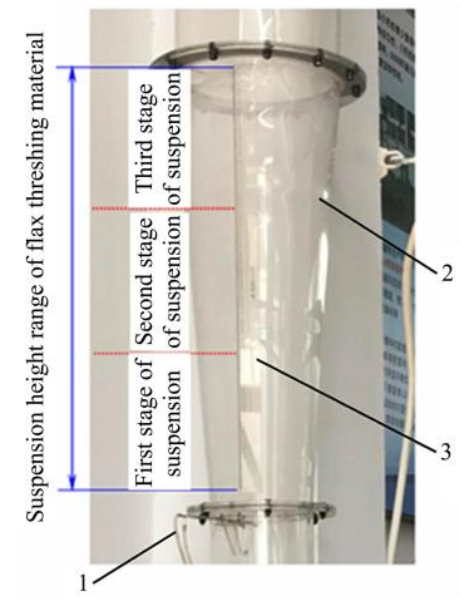

a. Flax threshing material suspension in three stages

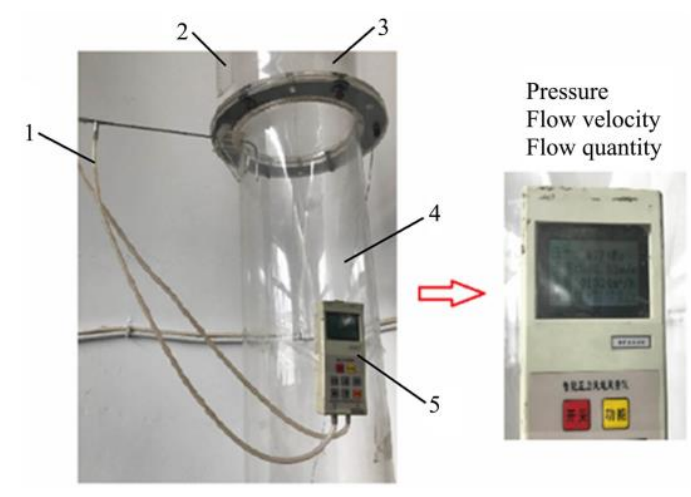

b. Parameters measured by the lower VR-tube

1. Pitot tube 2. Tapered observation tube 3. Suspension ruler 4. Lower VR-tube 5. Anemometer

Figure 2 Three stages of flax threshing material suspension velocity and parameter measurement

\section{Measurement of different components of flax threshing material}

\subsection{Test material preparation}

As shown in Figure 3, the test material was taken from the flax 
threshing material to be separated and cleaned after the operation of a small-scale thresher, the moisture content of threshing material was $11.6 \%$. The suspension velocity of the four components in the threshing material, namely grains, capsules, short stalks, and capsule husks, were measured. Through the collection and classification of the threshed flax material, $15 \mathrm{~g}$ of each component were weighed, bagged and sealed, and numbered. The suspension velocity of each component material was tested 3 times, and 6 test points were selected each time for the same stage of suspension velocity. Due to the inconsistency of the length of the stalks of the flax material after threshing, short stalks with a length of about $40 \mathrm{~mm}$ were selected from the flax threshing material to determine the suspension velocity when preparing the test material.

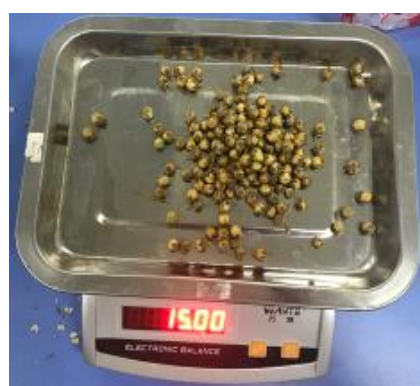

a. Capsule weighing

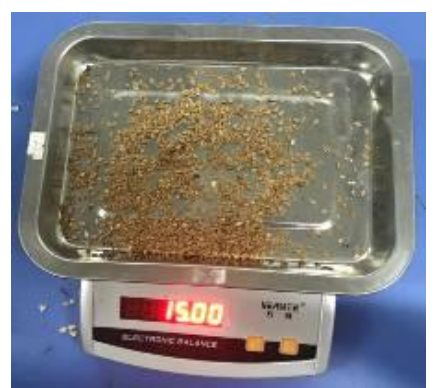

b. Grain weighing

\subsection{Measurement of different components of the flax threshing material}

In the process of measuring the suspension velocity of each component of flax threshing material, it is necessary to slowly adjust the frequency converter button to observe the suspension of different components of the material in the tapered observation tube (Figure 4). When the measured component material is suspended in the observation tube in the three different stages of height range, stop turning the button and record the fan speed, flow velocity and measure the height range of the material in dense suspension, and calculate the average value of the flow rate and the suspension height, and solve the suspension velocity of each component of flax threshing material based on Equation (1).

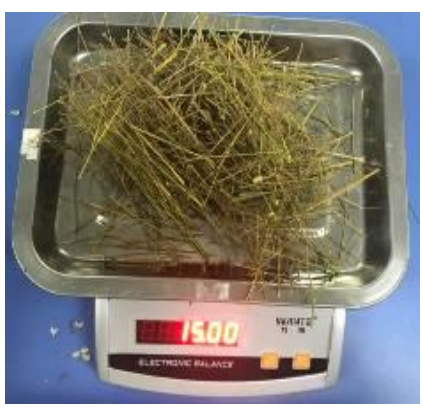

c. Stalk weighing

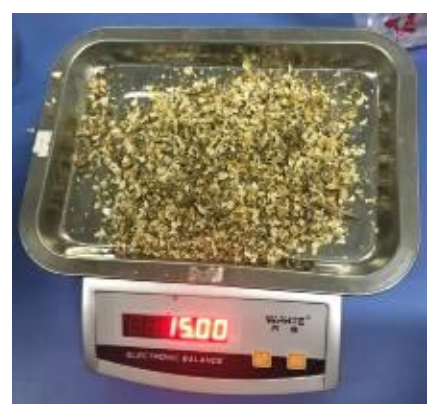

d. Capsule husk weighing

Figure 3 Weighing and classification of different components of the flax threshing material

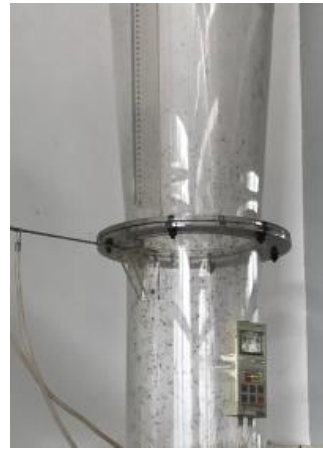

a. Grain in suspension

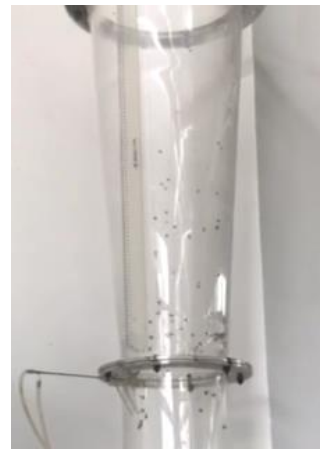

b. Capsules in suspension

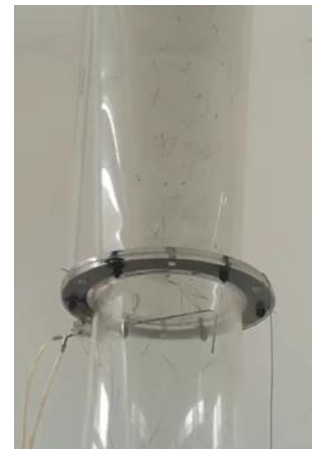

c. Short stalks in suspension

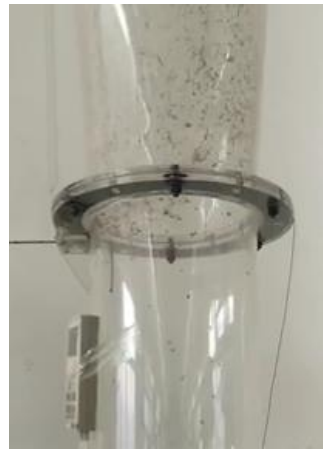

d. Capsule husks in suspension

Figure 4 Measurement process of different components of the flax threshing material

(1) Measurement of suspension velocity of flax grains. Combining the measurement results of related parameters of flax grain suspension velocity with Equation (1), the suspension velocity value of flax grain at each suspension stage is further calculated, as shown in Table 2. Among them, the fan speed when the grain suspension velocity was measured in three stages was $480 \mathrm{r} / \mathrm{min}, 513 \mathrm{r} / \mathrm{min}$ and $620 \mathrm{r} / \mathrm{min}$ respectively.

Table 2 Flax grain suspension velocity

\begin{tabular}{ccccc}
\hline Test No. & $\begin{array}{c}\text { Stages of } \\
\text { measurement }\end{array}$ & $\begin{array}{c}\text { Average flow } \\
\text { velocity/m·s }\end{array}$ & $\begin{array}{c}\text { Suspension } \\
\text { range/mm }\end{array}$ & $\begin{array}{c}\text { Suspension } \\
\text { velocity/m·s }\end{array}$ \\
\hline \multirow{2}{*}{1} & 1 & 5.63 & $0-280$ & $4.81-5.63$ \\
& 2 & 6.19 & $0-530$ & $4.65-6.19$ \\
2 & 3 & 8.28 & $0-940$ & $5.10-8.28$ \\
\hline \multirow{2}{*}{3} & 1 & 5.45 & $0-300$ & $4.61-5.45$ \\
& 2 & 6.03 & $0-520$ & $4.55-6.03$ \\
& 3 & 8.07 & $0-940$ & $4.97-8.07$ \\
\hline & 1 & 5.63 & $0-290$ & $4.79-5.63$ \\
& 2 & 6.20 & $0-480$ & $4.77-6.20$ \\
\hline
\end{tabular}

It can be seen from the test results that the suspension velocity of flax seeds in the first stage is between $4.61 \mathrm{~m} / \mathrm{s}$ and $5.63 \mathrm{~m} / \mathrm{s}$, the suspension velocity in the second stage is between $4.55 \mathrm{~m} / \mathrm{s}$ and $6.20 \mathrm{~m} / \mathrm{s}$, and the suspension velocity in the third stage is between $4.55 \mathrm{~m} / \mathrm{s}$ and $6.20 \mathrm{~m} / \mathrm{s}$. Therefore, the overall suspension speed of flax seeds is between $4.55 \mathrm{~m} / \mathrm{s}$ and $8.64 \mathrm{~m} / \mathrm{s}$. Among them, the suspension velocity of flax grains in the three stages overlaps each other, and this is mainly related to the size of the grains in the flax threshing material, the difference of plumpness and the degree of crushing, which affects the smoothness and uniformity of the flax grains as a whole, vibrating the grains up and down fiercely in the tapered observation tube, therefore, the range of the grain suspension velocity was large. By observing the suspension ruler during the three stages of suspension of flax grains, the grains have a distribution ranging from zero graduation to suspension height at corresponding stages. The reason is that, the flax grains are scattered material particles with good flowing property, resulting in a large range of suspension.

(2) Measurement of suspension velocity of flax capsules. Combining the parameters related to suspension velocity of flax capsules and Equation (1), the suspension velocity values of flax capsules at different suspension stages were calculated, as shown in Table 3. The fan speed at three stages of suspension height for flax capsules was set to the ranges of 590-620 r/min, 734-738 r/min 
and 823-863 r/min, respectively.

Table 3 Flax capsule suspension velocity

\begin{tabular}{ccccc}
\hline Test No. & $\begin{array}{c}\text { Stages of } \\
\text { measurement }\end{array}$ & $\begin{array}{c}\text { Average flow } \\
\text { velocity/m·s }\end{array}$ & $\begin{array}{c}\text { Suspension } \\
\text { range/mm }\end{array}$ & $\begin{array}{c}\text { Suspension } \\
\text { velocity/m· } \mathbf{s}^{-1}\end{array}$ \\
\hline \multirow{2}{*}{1} & 1 & 7.44 & $0-250$ & $6.46-7.44$ \\
& 2 & 9.51 & $0-560$ & $7.03-9.51$ \\
2 & 3 & 11.16 & $40-890$ & $7.04-10.90$ \\
\hline \multirow{2}{*}{3} & 1 & 7.73 & $0-270$ & $6.64-7.73$ \\
& 2 & 9.24 & $0-600$ & $6.70-9.24$ \\
& 3 & 10.58 & $38-900$ & $6.64-10.35$ \\
\hline & 1 & 7.79 & $0-270$ & $6.70-7.79$ \\
& 2 & 9.26 & $0-610$ & $6.68-9.26$ \\
\hline
\end{tabular}

It can be seen from the test results that the suspension velocity of flax capsules in the first stage is between 6.46-7.79 $\mathrm{m} / \mathrm{s}$, the suspension velocity in the second stage is between $6.68-9.51 \mathrm{~m} / \mathrm{s}$, and the suspension velocity in the third stage is between 6.57 $10.90 \mathrm{~m} / \mathrm{s}$. Therefore, the overall suspension speed of flax capsules is between $6.46-10.90 \mathrm{~m} / \mathrm{s}$. The same as the range of the suspension velocity of flax seeds, the three stages of the range of suspension velocity of flax capsules also overlap with each other. This is mainly related to the difference in the size of the capsules. The windward area of a capsule with a large particle size is larger, thus containing more grains within the capsule, requiring higher suspension velocity.

(3) Measurement of suspension velocity of short stalks. Combining the parameters related to suspension velocity of flax short stalks and Equation (1), the suspension velocity values of flax short stalks at different suspension stages were calculated, as shown in Table 4. The fan speed at three stages of suspension height for flax short stalks was set to the ranges of 327-347 r/min, 480-493 r/min and 632-668 r/min, respectively.

Table 4 Flax short stalk suspension velocity

\begin{tabular}{ccccc}
\hline Test No. & $\begin{array}{c}\text { Stages of } \\
\text { measurement }\end{array}$ & $\begin{array}{c}\text { Average flow } \\
\text { velocity } / \mathrm{m}^{-1}\end{array}$ & $\begin{array}{c}\text { Suspension } \\
\text { range/mm }\end{array}$ & $\begin{array}{c}\text { Suspension } \\
\text { velocity } / \mathrm{m} \cdot \mathrm{s}^{-1}\end{array}$ \\
\hline \multirow{2}{*}{1} & 1 & 4.11 & $0-440$ & $3.23-4.11$ \\
& 2 & 5.51 & $0-680$ & $3.84-5.51$ \\
2 & 3 & 7.79 & $60-980$ & $4.71-7.52$ \\
\hline \multirow{2}{*}{3} & 1 & 4.19 & $0-410$ & $3.34-4.19$ \\
& 2 & 5.70 & $0-700$ & $3.93-5.70$ \\
& 3 & 7.85 & $76-950$ & $4.82-7.51$ \\
\hline & 1 & 4.41 & $0-420$ & $3.50-4.41$ \\
& 2 & 5.73 & $0-682$ & $3.99-5.73$ \\
& 3 & 8.01 & $56-945$ & $4.93-7.75$ \\
\hline
\end{tabular}

It can be seen from the test results that the suspension velocity of flax short stalks in the first stage is between $3.2-\mathrm{m} / \mathrm{s}$, the suspension velocity in the second stage is between $3.84-5.73 \mathrm{~m} / \mathrm{s}$, and the suspension velocity in the third stage is between 4.71 $7.75 \mathrm{~m} / \mathrm{s}$. Therefore, the overall suspension velocity of flax short stalks is between $3.23-7.75 \mathrm{~m} / \mathrm{s}$. Since the flax stalks are about $40 \mathrm{~mm}$ in length at the neck of the flax plant with low small density and irregular shape, so the suspension velocity of the three stages is relatively small. When there are few stalks on in the material holding net and there are granular intervals among them, the flax stalks will not be agglomerated and suspended. If more flax stems are added, stalk aggregation will occur (Figure 5). Therefore, in the subsequent design of the air-flow separation and cleaning operation device for flax threshing material, the feeding amount of the flax threshing material should not be too much.
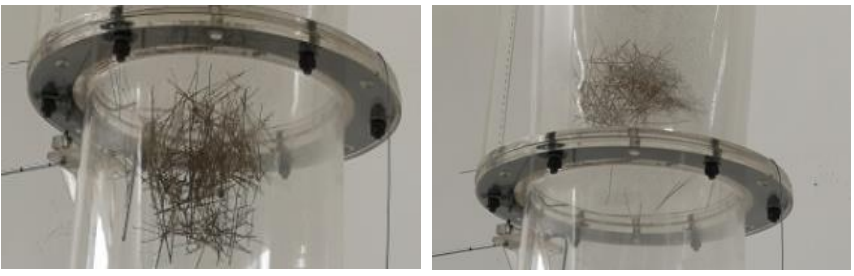

Figure 5 Suspension and agglomeration of flax stem

(4) Measurement of suspension velocity of flax capsule husks. Combining the parameters related to suspension velocity of flax capsule husks and Equation (1), the suspension velocity values of flax capsule husks at different suspension stages were calculated, as shown in Table 5. The fan speed at three stages of suspension height for flax capsule husks was set to the ranges of 142-151 r/min, 190-210 r/min and 286-300 r/min, respectively.

Table 5 Flax capsule husk suspension velocity

\begin{tabular}{ccccc}
\hline Test No. & $\begin{array}{c}\text { Stages of } \\
\text { measurement }\end{array}$ & $\begin{array}{c}\text { Average flow } \\
\text { velocity } / \mathrm{m}^{-1}\end{array}$ & $\begin{array}{c}\text { Suspension } \\
\text { range/mm }\end{array}$ & $\begin{array}{c}\text { Suspension } \\
\text { velocity } / \mathrm{m} \cdot \mathrm{s}^{-1}\end{array}$ \\
\hline \multirow{2}{*}{1} & 1 & 1.38 & $0-380$ & $1.12-1.38$ \\
& 2 & 2.59 & $0-700$ & $1.50-2.59$ \\
2 & 1 & 4.21 & $0-960$ & $2.57-4.21$ \\
\hline \multirow{2}{*}{3} & 2 & 1.34 & $0-420$ & $1.06-1.34$ \\
& 3 & 2.23 & $0-710$ & $1.53-2.23$ \\
& 1 & 4.21 & $0-950$ & $2.58-4.21$ \\
\hline & 2 & 1.47 & $0-390$ & $1.19-1.47$ \\
& 3 & 2.39 & $0-708$ & $1.64-2.39$ \\
\hline
\end{tabular}

It can be seen from the test results that the suspension velocity of flax capsule husks in the first stage is between $1.06-1.47 \mathrm{~m} / \mathrm{s}$, the suspension velocity in the second stage is between $1.50-2.59 \mathrm{~m} / \mathrm{s}$, and the suspension velocity in the third stage is between 2.52$4.21 \mathrm{~m} / \mathrm{s}$. Therefore, the overall suspension speed of flax capsule husks is between $1.06-4.21 \mathrm{~m} / \mathrm{s}$. Since the broken shape of the flax capsule husks is mostly one-third or one-fourth of the volume of the whole husk, the windward area is relatively large, but with low density and low weight, so the overall suspension velocity was not high.

\subsection{Comparative analysis of different components of the flax threshing material}

Figure 6 shows the distribution of the overall suspension velocity of flax grains, capsules, short stalks and capsule husks in the flax threshing material during the harvest period of Longya No.14 flax respectively.

It can be seen from the analysis results that the suspension velocity of each component of the flax threshing material at different stages basically shows a relatively increasing trend; when the minimum suspension velocity of each component changes from the first stage to the third stage, the suspension velocity is relatively small, especially for the flax grains and flax capsules, the minimum values of their suspension velocity at the three stages are basically close, the suspension velocity of the flax grains are 4.55-4.97 m/s, and that of the flax capsules are $6.46-6.68 \mathrm{~m} / \mathrm{s}$; but for the four materials, the maximum values of the suspension velocity of the components in the third stage have obvious changing trends. It can be seen from the distribution of the suspension velocity of each component of the flax threshing material that the suspension velocity of flax capsules is the highest regardless of the minimum or maximum values, followed by flax grains, short stalks, and finally flax capsule husks. Among the four types of flax threshing material components, when the air-flow separation and cleaning 
method is used for operation, the flax capsules cannot be effectively separated, so the flax capsules in the flax threshing material should be as few as possible; if the air sieve separation is used for cleaning in the selection method, the flax capsule components must be effectively screened and separated before the flax threshing material enters the cleaning device. At the same time, the difference in the suspension velocity of flax grains and short stalks is relatively small. Therefore, when the flax threshing material is separated and cleaned by airflow, in order to

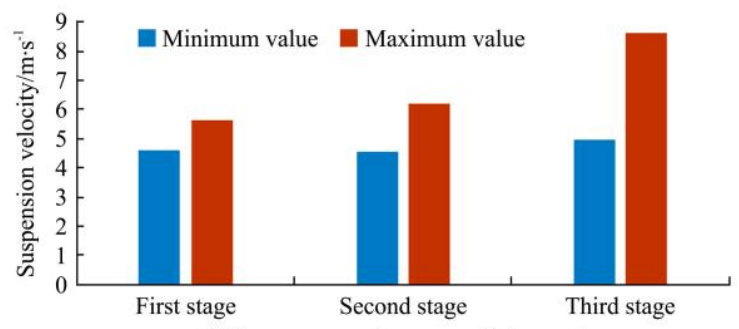

Different suspension stage of short stalks

a. Distribution of suspension velocity of flax grains



Different suspension stage of short stalks

c. Distribution of suspension velocity of short stalks

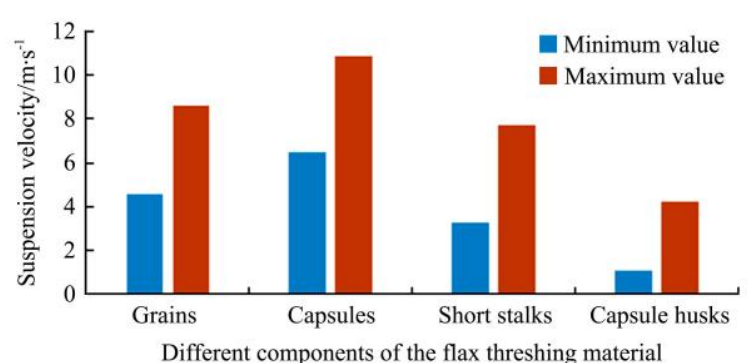

e. Distribution of different components of the flax threshing material fully separate the flax grains and short stalks, the length of the flax stalks should be reduced as much as possible to lower down the suspension velocity of the short stalks; or adopt a vibrating screen body with meshes of different sizes and types according to the different sizes of the two components, to better separate the grains and the stalks. The suspension velocity distribution of each component of the flax threshing material (Figure 6) can also reflect its characteristics of mixed material with small differences.

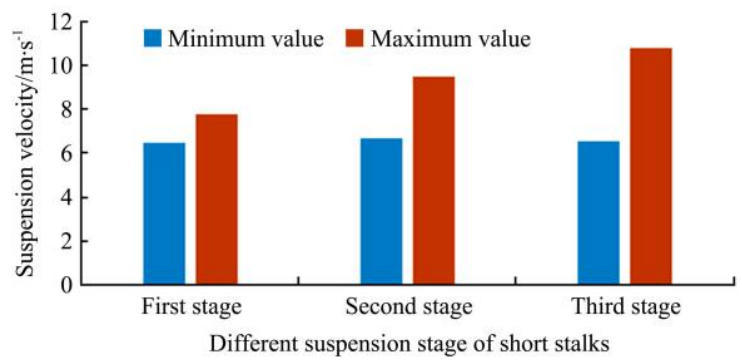

b. Distribution of suspension velocity of flax capsules

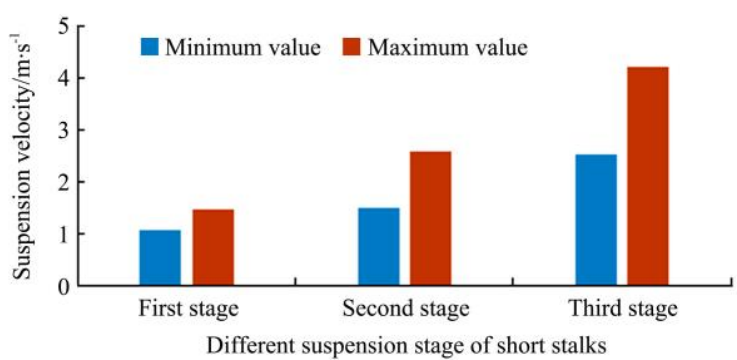

d. Distribution of suspension velocity of flax capsule husks

\section{Measurement and numerical simulation of the suspension velocity of flax threshing material}

\subsection{Material model and parameter setting}

According to the components of the flax threshing material, the simulation mainly analyzes flax grains, capsules, short stalks and capsule husks, the shapes of which are different (Figure 7). The multi-spherical particle filling method in EDEM was used to fit the shape of different shapes of material. The geometric dimension parameters, material attribute parameters, recovery coefficient, static friction factor, dynamic friction factor and the number of generated particles per unit time can be found ${ }^{[15]}$.

In the simulation setting, the pellet factory of flax threshing material in the EDEM software is located at the bottom end of the floating tube, which is a cylindrical tube with a radius of $120 \mathrm{~mm}$ and a height of $50 \mathrm{~mm}$. The static generation method was selected to generate various materials, which move from the bottom of the floating tube to the tapered observation tube. The simulation lasted for $9 \mathrm{~s}$ in total, and the time step was $3 \times 10^{-6} \mathrm{~s}$; the $k$-e turbulence model was selected in the Fluent software, and the free flow drag model was used in the gas-solid coupling, and the time step was $3 \times 10^{-4} \mathrm{~s}$.
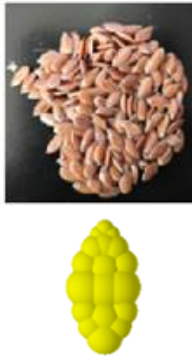

a. Grains
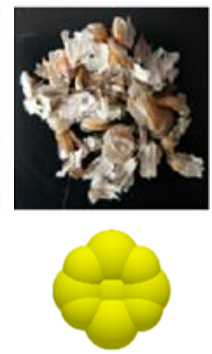

b. Capsule shells

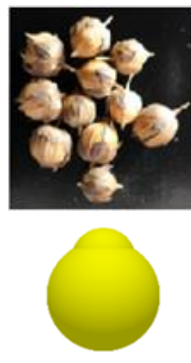

c. Capsules
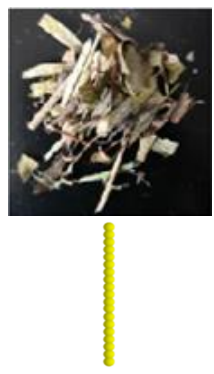

Figure 7 Different components of flax threshing material and their discrete element model

\subsection{Verification of the material model}

EDEM software was used to measure the angle of repose of each component of the flax threshing material (Figure 8) and the sliding friction angle between each component of the flax threshing material and the steel (Figure 9). The Hertz-Mindlin (no slip) contact model was selected, and the Rayleigh time step was set to $20 \%$, the data 
saving interval was $0.01 \mathrm{~s}^{[16,17]}$.

After finishing simulation of the sliding of the components of the flax threshing material, adjust the model to the front view angle, and use the Screen Protractor 4.0 tool to measure the angle of repose of each component and the sliding friction angle of each component and the steel. It can be seen from the simulation test results that the simulated angle of repose angle of flax threshing material established by the discrete element method was $45.6^{\circ}$, the simulated angle of repose of threshing material is $50.3^{\circ}$, and the simulated angle of repose of clearing seeds is $31.8^{\circ}$; the established simulated sliding angle of flax threshing material and steel by the discrete element method was $28.8^{\circ}$, that of threshing material residue and steel was $35.8^{\circ}$, and that of cleaned grains and steel was $21.8^{\circ}$, showing that there was not much difference between simulation results and the measured values of the angle of repose of flax threshing material $\left(46.2^{\circ}, 51.6^{\circ}, 31.1^{\circ}\right)$, and the measured values of the sliding angle of flax threshing material $\left(29.2^{\circ}, 36.6^{\circ}\right.$, $\left.21.5^{\circ}\right)^{[18]}$ and the established discrete element model of flax threshing material and its different components are basically reliable, and the models can be used for the subsequent discrete element simulation analysis on the separation and cleaning process of related flax threshing material.

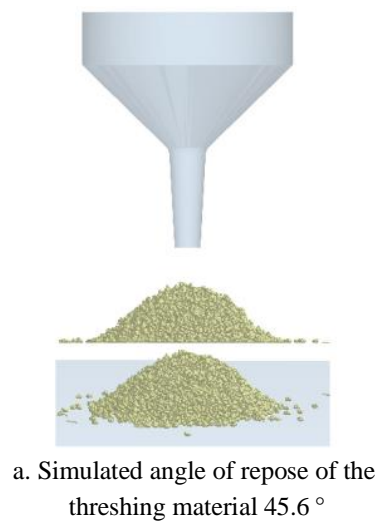

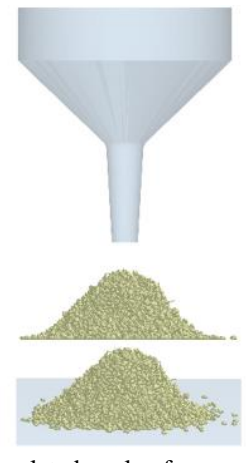

b. Simulated angle of repose of the material residue $50.3^{\circ}$

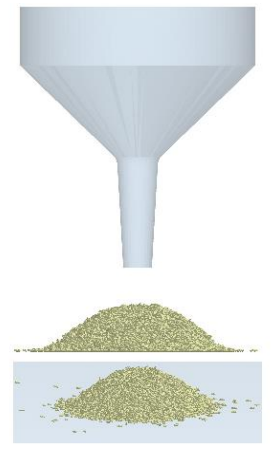

c. Simulated angle of repose of cleaned grains $31.8^{\circ}$

Figure 8 Simulated angle of repose of flax threshing material and different components

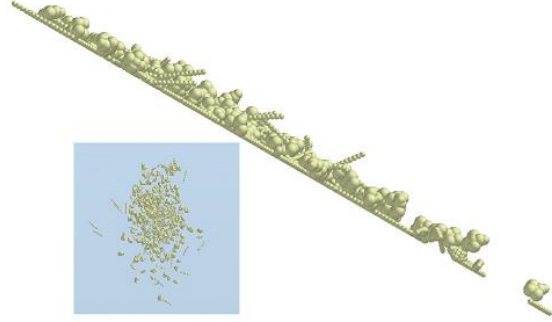

a. Simulated sliding angle between the threshing material and steel $28.8^{\circ}$

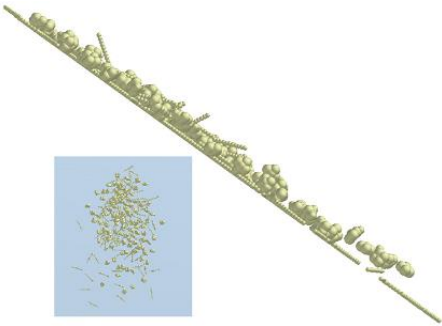

b. Simulated sliding angle between the material residue and steel $35.8^{\circ}$

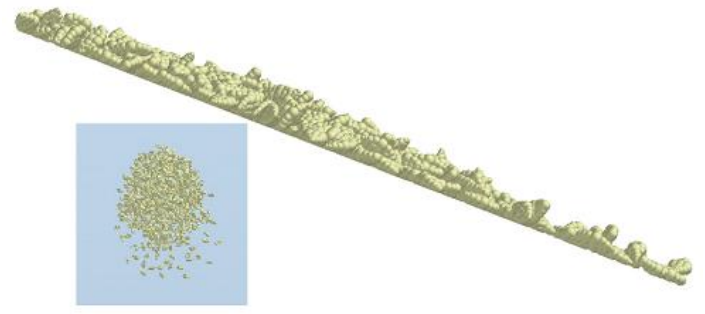

c. Simulated sliding angle between the cleaned grains and steel $21.8^{\circ}$

Figure 9 Sliding friction angle simulation of flax threshing material and its different components with steel

4.3 Simulation measurement of the suspension velocity of different components of flax threshing material

The suspension velocity of different components of flax threshing material was measured by simulation based on the CFD-DEM theory. The existing research results show that, if the wind speed of the material suspension velocity measuring device was set to be too high, the particle group would flow out directly from the outlet, and if the wind speed is too low, the particle group would stay at the material platform and cannot go up through the steady flow section ${ }^{[19]}$. Since the simulation measurement methods and approaches are the same, the numerical simulation effects of different components of material in different suspension stages are similar. Therefore, this study makes specifications and numerical verification of the simulation effects on the flax threshing material at the medium position in the suspension area (between the first and the second suspension stage). The simulation measurement process shows that when the four types of material (grains, capsules, short stalks, and capsule husks) had an inlet wind speed of $5.3 \mathrm{~m} / \mathrm{s}, 6.8 \mathrm{~m} / \mathrm{s}, 4.2 \mathrm{~m} / \mathrm{s}$ and $1.3 \mathrm{~m} / \mathrm{s}$, respectively, each component of flax threshing material could rise from the lower VR-tube to the tapered observation tube. It was found in the test that most of the materials were attached to the inner wall of the tapered observation tube under the action of airflow in a stable suspension state, with only a few parts of the material suspending up and down in a certain area of the pipe wall, as shown in Figure 9. The main reason for the phenomenon above is: with the pressure difference on the surface of the particles of each component of the flax threshing material under airflow, the airflow will push the particles of each component up while also pushing them to move toward the wall of the tapered observation tube. When the air velocity near the pipe wall was less than the suspension velocity of the particles of each component of the threshing material, the particles will immediately have a tendency to fall and fall down along the inclined wall of the tapered observation tube, resulting in a horizontal acceleration toward the center of the tube. When the threshing material particles slid down to the area where the airflow velocity was greater than the suspension velocity, the particles would rise again, followed by circulating in sequence, and finally adhere to the tapered tube wall to form a closed ring structure, as shown in Figure $10^{[19-22]}$. In addition, considering the fact that the weight of flax capsule husks is slightly lighter than that of other components, the suspension height of flax capsule husks measured by the suspension speed was relatively higher than that of the other three components, showing that it is consistent with the measurement process in actual test. 


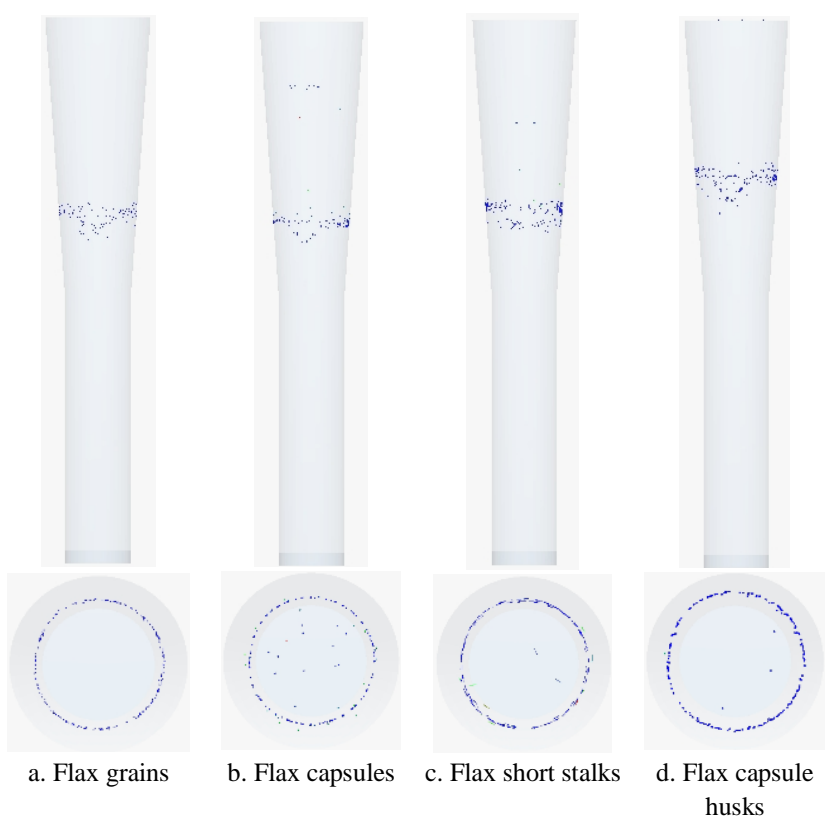

Figure 10 Simulation measurement process of suspension velocity of different components of the flax threshing material

\section{Simulation results analysis of suspension velocity of different components of flax threshing material}

When the flax threshing material particles were in a stable suspension state in the tapered observation tube, the flow field velocity calculated in the Fluent software and the particle velocity of each component in the EDEM software were imported into the

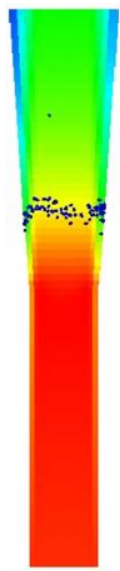

Flax seeds velocity $/ \mathrm{m} \cdot \mathrm{s}^{-1}$

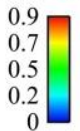

Fluid velocity $/ \mathrm{m} \cdot \mathrm{s}^{-1}$

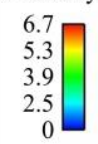

Flax grains

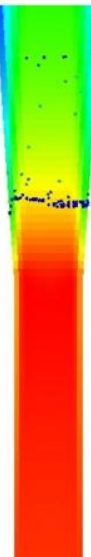

Capsules velocity $/ \mathrm{m} \cdot \mathrm{s}^{-1}$



0.8
0.4
0

Fluid velocity $/ \mathrm{m} \cdot \mathrm{s}^{-1}$

9.4
7.7
6.0
4.3
0

post-processing software for gas-solid coupling flow field analysis. The suspension position of the component particles in the tapered observation tube was used to obtain the air flow velocity at the different corresponding positions for the components of the flax threshing material. The moderate suspension position of the different components of the flax threshing material and the corresponding velocity flow field distribution are shown in Figure 11.

It can be seen from Figure 11 that in the tapered observation tube, most of the particles of different component particle groups are blue, and they are basically in discrete suspension at the moderate position between the first and the second suspension stage. Most particles gather in a relatively stable suspension position; affected by the shape, windward area and surface characteristics of the material, only a small part of the material particles was in the higher suspension position of the tapered observation tube. According to the coordinates of the suspension positions of the particles, the air velocity at the corresponding position was obtained. The suspension velocity of the grains in the flax threshing material was $4.8-5.7 \mathrm{~m} / \mathrm{s}$; the suspension velocity of the capsule was $6.6-8.2 \mathrm{~m} / \mathrm{s}$; the suspension velocity of short stalks was $5.1-5.5 \mathrm{~m} / \mathrm{s}$; the suspension velocity of capsule husks was $1.4-2.2 \mathrm{~m} / \mathrm{s}$. The simulation measurement results were within the measurement result range in actual tests, so the simulation results are consistent with the actual test results. It showed that the simulation on the suspension velocity of different components of flax threshing material based on gas-solid coupling had high precision degree. Therefore, the feasibility of the suspension velocity of the flax threshing material measured in the simulation test based on CFD-DEM coupling was verified.



c. Flax short stalks

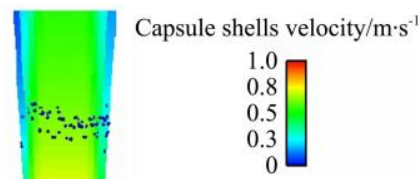

Fluid velocity $/ \mathrm{m} \cdot \mathrm{s}^{-1}$

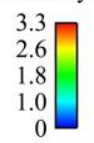

\section{Conclusions}

1) Based on the material suspension velocity measuring device, the suspension velocity of flax grains, capsules, short stalks and capsule husks in the flax threshing material during the harvest period of Longya No.14 was measured. Among them, the suspension velocity of flax grains was $4.55-8.64 \mathrm{~m} / \mathrm{s}$, the suspension velocity of flax capsules was $6.46-10.90 \mathrm{~m} / \mathrm{s}$, and the suspension velocity of flax short stalks was $3.23-7.75 \mathrm{~m} / \mathrm{s}$, the suspension velocity of the capsule husks was $1.06-4.21 \mathrm{~m} / \mathrm{s}$. The distribution of the overall suspension velocity of different components of the flax threshing material and their separation characteristics were obtained.

2) The discrete element model of each component of flax threshing material was established, and the angle of repose of flax threshing material, angle of repose of material residue and the angle of repose of cleaned grains were measured by simulation $\left(45.6^{\circ}, \quad 50.3^{\circ}\right.$ and $31.8^{\circ}$ respectively). The simulation measurement of the sliding friction angle of each component and steel (respectively $28.8^{\circ}, 35.8^{\circ}$ and $21.8^{\circ}$ ) verified the reliability of the established model.

3) The suspension velocity of each component of the flax threshing material was simulated based on the CFD-DEM gas-solid coupling method. Through the two-phase flow coupling calculation, the suspension velocity of the grains was $4.8-5.7 \mathrm{~m} / \mathrm{s}$; the suspension velocity of the capsules was $6.6-8.2 \mathrm{~m} / \mathrm{s}$; the suspension velocity of short stalks was $5.1-5.5 \mathrm{~m} / \mathrm{s}$; the suspension velocity of the capsule husks was $1.4-2.2 \mathrm{~m} / \mathrm{s}$. The simulation results of the suspension velocity of each component were included in the range of actual test measurement results. 


\section{Acknowledgements}

The authors acknowledge that this work was financially supported by China Agriculture Research System of MOF and MARA (Grant No. CARS-14-1-28), Fuxi Young Talents Fund of Gansu Agricultural University (GaufX-03Y01), Key Research and Development Program of Gansu Province (20YF3WA019).

\section{[References]}

[1] Hou H M, Cui Q L, Guo Y M, Zhang Y Q, Sun D, Lai S T, Liu J L. Design and test of air-sweeping suspension velocity testing device for cleaning threshed materials of grain and oil crops. Transactions of the CSAE, 2018; 34(16): 43-49. (in Chinese)

[2] He Y, Bayly A E, Hassanpour A L. Coupling CFD-DEM with dynamic meshing: A new approach forfluid-structure interaction in particle-fluid flows. Powder Technology, 2018; 325: 620-631.

[3] Gorial B Y. Aerodynamic properties of grain/straw materials. Journal of Agricultural Engineering Research, 1990; 46: 275-290.

[4] Ragab K, Pan Z L, Atungulu G G. Characterization of physical and aerodynamic properties of walnuts. ASABE 2012 Annual Meeting, Paper No. 121338051, Dallas, Texas, USA, 2012.

[5] Gao L X, Zhang W, Du X, Liu X, Yang J, Liu G M. Experiment on aerodynamic characteristics of threshed mixtures of peanut shelling machine. Transactions of the CSAE, 2012; 28(2): 289-292. (in Chinese)

[6] Cao C M, Luo K, Peng M L, Wu Z M, Liu G Z, Li Z. Experiment on winnowing mechanism and winnowing performance of hickory material. Transactions of the CSAE, 2019; 50(9): 105-112. (in Chinese)

[7] $\mathrm{Ma} \mathrm{Z}, \mathrm{Li} \mathrm{Y} \mathrm{M,} \mathrm{Xu} \mathrm{L} \mathrm{Z.} \mathrm{Testing} \mathrm{and} \mathrm{analysis} \mathrm{on} \mathrm{rape} \mathrm{excursion}$ components characteristics in floating, friction and wettability. Transactions of the CSAE, 2011; 27(9): 13-17. (in Chinese)

[8] Su W, Gao X J, Ren C, Lai Q H. A simulation prediction method of suspension speed of seed particle swarm. Journal of South China Agricultural University, 2016; 37(1): 110-116. (in Chinese)

[9] Yu F F, Li P, Zhang F K, Zhang H, Li Z J, Fan X W. Design and test of measuring device for red jujube material suspension speed. Journal of Chinese Agricultural Mechanization, 2020; 41(9): 89-94. (in Chinese)

[10] Chen L, Liao Q X, Zong W Y, Liao Y T, Li H T, Huang P. Aerodynamic characteristics measurement of extraction components for rape combine harvester. Transactions of the CSAE, 2012; 43(Z1): 125-130.

[11] Mekonnen Gebreslasie Gebrehiwot, Josse de Baerdemaeker, Martine Baelmans. Numerical and experiment study of a cross-flow fan for combine cleaning shoes. Biosystems Engineering, 2010; 106(4): 448-457.

[12] Yuan J B, Wu C Y, Li H, Qi X D, Xiao X X, Shi X X. Movement rules and screening characteristics of rice-threshed mixture separation through a cylinder sieve. Computers and Electronics in Agriculture, 2018; 154: 320-329.

[13] Jiang E C, Sun Z F, Pan Z Y, Wang L J. Numerical simulation based on CFD-DEM and experiment of grain moving laws in inertia separation chamber. Transactions of the CSAE, 2014; 45(4): 117-122. (in Chinese)

[14] Dai F, Song X F, Guo W J, Zhao W Y, Zhang F W, Zhang S L. Simulation and test on separating cleaning process of flax threshing material based on gas-solid coupling theory. Int J Agric \& Biol Eng, 2020; 13(1): 73-81.

[15] Dai F. Study on the separating-cleaning mechanism and key technology of flax threshing material. Lanzhou: Gansu Agricultural University, 2020. (in Chinese)

[16] Sebastian R, Shkelqim K, Joachim M. Discrete element method simulation of the hulling process of Jatropha curcas L. fruits. Biosystems Engineering, 2017; 155: 55-67.

[17] Coetzee C J. Calibration of the discrete element method and the effect of particle shape. Power Technology, 2016; 297: 50-70.

[18] Dai F, Zhao W Y, Song X F, Shi R J, Liu G C, Wei B. Parameter optimization and experiment on separating and cleaning machine for flax threshing material. Transactions of the CSAE, 2020; 51(8): 140-147. (in Chinese)

[19] Wen X Y, Jia H L, Zhang S W, Yuan H F, Wang G, Chen T Y. Test of suspension velocity of granular fertilizer based on EDEM-Fluent coupling. Transactions of the CSAE, 2020; 51(3): 69-77. (in Chinese)

[20] Wang S Y, Li H L, Wang R C, Wang X, Tian R C, Sun Q J. Effect of the inlet angle on the performance of a cyclone separator using CFD-DEM. Advanced Powder Technology, 2019; 30(2): 227-239.

[21] Peng Z B, Doroodchi E, Moghtaderi B, Evans G M. A DEM-based analysis of the influence of aggregate structure on suspension shear yield stress. Advanced Powder Technology, 2012; 23(4): 437-444.

[22] Dai F, Song X F, Shi R J, Zhao W Y, Guo W J, Zhang Y. Migration law of flax threshing materials in double channel air-and-screen separating cleaner. Int J Agric \& Biol Eng, 2021; 14(3): 92-102. 